\title{
Building competence in radiation and nuclear safety through education and training - the approach of a national regulatory authority
}

\author{
K.L. Karfopoulos`, E. Carinou, V. Kamenopoulou, P. Dimitriou and Ch. Housiadas \\ Greek Atomic Energy Commission, P.O. Box 60092, 15310 Agia Paraskevi, Greece.
}

Received 9 April 2014 - Accepted 21 October 2014

\begin{abstract}
The Greek Atomic Energy Commission (EEAE) is the national competent authority for radiation and nuclear safety and security as well as for the radiation protection of ionizing and artificially produced non-ionizing radiation. The legal framework determines, inter alia, the responsibilities in education and training issues. The EEAE has a range of activities, in providing postgraduate and continuous education and training on radiation protection, and nuclear safety and security, at the national and international levels. At the national level, and particularly in the medical field, the EEAE is a participant in and a major contributor to the Inter-University Postgraduate Program on Medical Radiation Physics. Since 2003, the EEAE has been the Regional Training Center (RTC) for radiation, transport and waste safety of the International Atomic Energy Agency (IAEA) for the European Region in the English language. Moreover, the EEAE has also been recognized as the IAEA's Regional Training Center (RTC) in nuclear security in the English language since 2013. The EEAE recently proceeded to two significant initiatives: the design of a national program for education and training, and the certification of the Department of Education according to ISO 29990:2010. In this paper, the initiatives taken to enhance the radiation protection system in the country through education and training are presented.
\end{abstract}

Keywords: education / training / radiation protection / regional training center

\section{Introduction}

The Greek Atomic Energy Commission (EEAE) is the competent national regulatory authority in the fields of radiation and nuclear safety. The EEAE's mission is the protection of the public, workers and the environment from ionizing and artificially produced non-ionizing radiation. The use of ionizing radiation in the country is widespread in medical practice for diagnosis and therapy, in industry, scientific research, etc. The medical sector covers more than $90 \%$ of the relevant applications.

The EEAE's responsibility is to establish and supervise the implementation of a sustainable radiation protection program in the country. An efficient and effective radiation protection system is an ongoing procedure based on the experience and knowledge of the individuals participating in this effort. Therefore, it is undoubtedly necessary that the people involved occupationally in procedures using ionizing radiation are appropriately educated and trained on radiation protection issues. This necessity is clearly stated in the Greek Radiation Protection Regulations (GRPR, 2001). It is also mentioned in an emphatic way in the new European Council Directive concerning

\footnotetext{
* kkarfop@eeae.gr
}

the basic safety standards (new EC BSS, Chap. IV, Art. 14) (Council Directive, 2013), while the significance of education and training and the importance of the establishment of a sustainable education and training program is emphasized as well. In this respect, one of the EEAE's major challenges is the provision of continuous education and training to occupationally exposed workers.

The EEAE has an important role in providing education and training specifically in the field of medical radiation protection in the country. The beginning of the EEAE's educational activities coincided with the establishment of the foundation of the Hospital Physicists' Postgraduate School at the beginning of 1960. In order to fulfill the educational needs in radiation protection, partnerships with other international and national educational institutions and professional bodies were established. The EEAE's educational activities are fully supported by its experienced scientific personnel, its state-of-theart technical infrastructure and the collaborative educational and research centers.

The EEAE has acted as the IAEA's Regional Training Center (RTC) for radiation, transport and waste safety in Europe in the English language since 2003 and was recognized as an IAEA RTC for nuclear security in the English language in 2013. 
In this work, the educational role of the EEAE and the initiatives taken to cover the national needs for education and training are described. Moreover, emphasis is given to the regional and international activities in education and training.

\section{Education and training at the National level}

The GRPR (2001) require that the persons involved in the practical aspects of radiological procedures shall have knowledge of radiation protection and adequate theoretical and practical training. The EEAE issues certificates of competence to occupationally exposed personnel or recognizes corresponding diplomas or certificates awarded on the basis of the authorized curricula. Moreover, there are provisions for continuous training in the field of radiation protection, addressing in this way the educational needs arising from the introduction of new techniques. Furthermore, the EEAE encourages the introduction of radiation protection courses to medical and dental schools at undergraduate level. In the GRPR it is also stated that a person can only be employed in professions dealing with ionizing radiation if his/her radiation protection training has been approved by the EEAE.

Under this legal framework the EEAE undertakes initiatives at the national level covering all the spectrum of applications and facilities of ionizing radiation. In the medical field, the EEAE, since 1994, has been a participant in and a major contributor to the Inter-University Postgraduate Course on Medical Radiation Physics (PGCMRP syllabus) ${ }^{1}$. This course is organized by the Universities of Athens, Ioannina, Thessaloniki, Crete and Thrace in collaboration with the EEAE and the National Center for Scientific Research (NCSR) "Demokritos", aiming at specialized training of physicists in Medical Radiation Physics. The course is attended by 10 to 15 students annually, depending on the national needs. This course leads to a Master's Degree, which is one of the prerequisite qualifications for the candidates along with the one-year on-the-job training in order to get the relevant professional license, issued by the Ministry of Health. The EEAE invests in highly qualified Medical Physicists who can play an important role in the implementation of education and training programs and the establishment of a safety culture in the medical field. These Medical Physicists should be capable of acting as Medical Physics Experts in the field of medical exposure according to the MED 97/43 EURATOM Directive (Council Directive, 1997) or according to the article 83 of the new EC BSS (Council Directive, 2013) and provide advice and highstandard services within the medical radiation laboratories. In addition, following specialized training, they can act as Qualified Experts according to the BSS 96/29 EURATOM

Directive (Council Directive, 1996) or as Radiation Protection Experts according to Article 82 of the (Council Directive, 2013), in radiation protection and safety of radiation sources in fields other than medical, covering the relevant needs of the country. Medical Physicists have a key role in enhancing the sustainability of the radiation protection system in Greece.

The Article 18 of the new EC BSS (Council Directive, 2013 ) is dedicated to education, information and training in the

1 http://www.eeae.gr/en/index.php?fvar=html/edu/_msc field of medical exposure. Taking into account the non-medical personnel related to medical exposure, the EEAE recently (2010-2011) organized and accomplished a nationwide extensive education and training project, dealing with several cycles of three-day courses on radiation protection in medicine, addressed to medical technologists, which was implemented in collaboration with academic institutions and locally with the Medical Physics Departments of Universities and major General Hospitals. In total, 2500 medical technologists attended these courses. For the purposes of these courses, special educational material was developed (a textbook and presentation files). This material is available on the EEAE's web page, free of charge. Since then, written examinations have been performed periodically, leading to a certificate of knowledge competency on radiation protection in medical applications. In total, 3000 non-medical personnel have succeeded in the exams and received the certificate. This kind of examination is going to be continued until 2016.

Industrial applications cover about $10 \%$ (in terms of occupationally exposed personnel) of the applications of ionizing radiation in the country. The EEAE through its training activities aims at the development of a safety culture in this area as well. To this end, the EEAE has designed a series of two-day seminars on radiation protection in industrial radiography. The seminars were attended by more than 100 radiographers and assistant radiographers. The seminars were conducted either as an EEAE initiative or as a demand from third parties (e.g. industrial radiography laboratories). This initiative is still in progress. On-the-job training activities have been added within the syllabus.

The EEAE, on the occasion of the Athens 2004 Olympic Games (Kamenopoulou et al., 2006) provided training on radiation protection, prevention, detection, and emergency preparedness and response to more than 3000 persons working for several national organizations involved in the national emergency plan (military forces, police, coast guards, fire brigade, first-line officers, etc.) and still continues to organize on a regular basis seminars addressed to the personnel of these organizations, in order to ensure the sustainability of national operational capability on emergency preparedness and response. In the case of customs officers, training courses on illicit trafficking have been conducted and refresher training courses have been planned for the near future at the customs offices all over the country in order to maintain and strengthen their skills and knowledge on detection equipment and relevant procedures. Basic elements of the syllabus used for the training of the customs officers and more details on their training can be found in (Pafilis et al., 2009).

Under the existing legal framework, the EEAE performs on-site inspections inter alia at the installations of the outside undertakings in order to verify compliance with the safety requirements. A lack of appropriate training in radiation protection and unawareness among the involved parties (undertakings, workers, operators) about their role, their responsibilities and their collaboration on certain issues were some of the findings of the inspections. The EEAE, in order to increase awareness among outside workers on radiation protection and to support the development of a safety culture among them, organized special training courses on radiation 
protection (Economides, 2013). The 8-hour courses covered theoretical aspects (physics and biological effects of ionizing radiation, dose monitoring program, the legislative framework for the outside workers) and practical aspects of radiation protection in medical applications, since the majority of the outside undertakings are companies installing or maintaining medical equipment. This initiative taken by the EEAE has covered $30 \%$ of the registered outside workers in the country so far; however, it is considered successful and contributes significantly to the enhancement of the national radiation protection system. Similar initiatives will be continued in the future.

Since 2007, the EEAE has systematically provided training on the safe transport of radioactive materials with the aim of informing and educating stakeholders in radiation protection. The attendance of the 1-day seminars is a prerequisite for the participation in the examinations organized by the Ministry of Infrastructure, Transport and Networks for the advisors for the safe transport of dangerous goods. In this respect, seminars are organized 3-4 times per year.

\section{National strategy in education and training}

The need for establishing a national strategy on education and training is explicitly stated in the IAEA general safety requirements (IAEA, 2010a, 2011) and the corresponding safety guides (IAEA, 2001a), while the objective of facilitating member states in the development and implementation of a national strategy for education and training is clearly defined in the IAEA Strategic Approach to education and training in radiation, transport and waste safety for the years 2011-2020.

The establishment of an effective and sustainable national Radiation Protection system demands an adequate number of trained personnel, which is the outcome of the implementation of a national strategy on education and training. Such a strategy contributes to the growth of national expertise through the development of national education and training programs, taking into account the existing and future needs, with regard to the national capabilities and resources. In this way, an optimization of the available resources can also be achieved.

Recently, the EEAE took the required initiatives in order to create a 3-year national program for education and training, based on the possibilities given by the national legislation. It should also be taken into account that the EEAE, as an IAEA RTC, was expected to be the leading country, providing its expertise and advice to other Member States in the region, on how to establish a national strategy. The details of this program, which was approved by the EEAE Board, can be found in (Dimitriou et al., 2013).

The implemented methodology (IAEA, 2010b) consists of four linked phases that provide the answers to key questions:

- Assessment of education and training needs, answering the question "What is needed?"

- Design of education and training program, answering the question "What is the education and training program that will meet the need?"

- Development and implementation of education and training program, answering the question "How is the education and training program to be established?"
- Evaluation of the effectiveness of the education and training program, answering the question "Is the established education and training program of value?"

In order to assess the training needs the EEAE takes advantage of the information and data included in the National Radiation Protection Database (NRPD). The database includes, among other data, information about the personal doses of occupationally exposed workers, as well as information about the radiation facilities and activities in Greece. An important aspect, crucial for the estimation of the education and training needs, is the fact that data concerning the educational level of the occupationally exposed workers are maintained in the NRPD as well. The existence and the level of quality of the NRDB data and structure were considered, in the recent Integrated Regulatory Review Service (IRRS) report to the Hellenic government, as a good practice (IRRS, 2012). To design and establish the national program, the EEAE took into account the existing national capabilities (human resources, facilities, financial circumstances) as well as the international support (e.g. support provided by the IAEA). Table 1 summarizes the national program for education and training. In this table, the kind and number of courses as well as the certificate to which each course leads are reported.

For the purposes of the national education and training program described, educational material has been developed. Depending on the seminar, syllabi, lecture plans, presentations, text books and/or laboratory exercises, on-the-job training activities and procedures for the assessment of the participants' competence have been developed. The curricula of the courses have taken into account the recommendations of international organizations (EC, IAEA, ICRP) (IAEA 2001b, 2002; ICRP, 2009; EC, 2010) and are approved by the EEAE's board.

The successful implementation of the national program requires the support of other national organizations as well. Thus, in line with its organizational values, the EEAE identified the need to form a national network of collaborating institutions in order to provide high-quality services in the field of radiation safety education and training. This network constitutes:

- the National Center of Scientific Research "Demokritos", including the research reactor, the TANDEM accelerator, the non-destructive testing facility, the interim waste storage facility, the production of isotopes and the biodosimetry laboratory;

- the Faculties of Medicine and Physics of the University of Athens;

- the National Technical University of Athens, Nuclear Engineering Department of the School of Mechanical Engineering;

- the Faculty of Medicine of the University of Ioannina.

The EEAE has established specific requirements for the trainers that correspond to a specific educational background and experience level. Mechanisms for evaluating the efficiency and effectiveness of its national program are in place as described in Section 5. 
Table 1. The national program for education and training as approved by the Board of the EEAE.

\begin{tabular}{|c|c|c|c|c|}
\hline $\begin{array}{l}\text { Practice/ } \\
\text { Activities }\end{array}$ & $\begin{array}{c}\text { Category } \\
\text { of personnel }\end{array}$ & $\begin{array}{l}\text { Training } \\
\text { cours }\end{array}$ & $\begin{array}{l}\text { Number of } \\
\text { training courses }\end{array}$ & Leading to \\
\hline $\begin{array}{l}\text { Medical Physics } \\
\text { applications }\end{array}$ & MPE & $\begin{array}{c}\text { Inter - University } \\
\text { Postgraduate Course in } \\
\text { Medical - Radiation Physics }\end{array}$ & 3 & MSc \\
\hline $\begin{array}{c}\text { Relevant to all } \\
\text { practices/activities }\end{array}$ & RPE & $\begin{array}{c}\text { IAEA Postgraduate } \\
\text { Educational Course on } \\
\text { Radiation Protection and } \\
\text { the Safety of Radiation Sources }\end{array}$ & 1 & $\begin{array}{c}\text { Certificate } \\
\text { of participation }\end{array}$ \\
\hline $\begin{array}{l}\text { Interventional } \\
\text { Radiology }\end{array}$ & $\begin{array}{l}\text { Radiation Health } \\
\text { Professionals }\end{array}$ & $\begin{array}{c}\text { Radiation Protection } \\
\text { in Interventional Cardiology }\end{array}$ & 3 & $\begin{array}{c}\text { Certificate } \\
\text { of competence }\end{array}$ \\
\hline $\begin{array}{l}\text { Interventional } \\
\text { Radiology }\end{array}$ & Technologists & $\begin{array}{l}\text { Radiation Protection } \\
\text { in Interventional Radiology }\end{array}$ & 3 & $\begin{array}{c}\text { Certificate } \\
\text { of participation }\end{array}$ \\
\hline $\begin{array}{c}\text { Transfer of } \\
\text { Radioactive Material }\end{array}$ & $\begin{array}{l}\text { Advisors for the transportation } \\
\text { of dangerous goods }\end{array}$ & $\begin{array}{l}\text { Transportation } \\
\text { of class } 7 \text { goods }\end{array}$ & 12 & $\begin{array}{c}\text { Certificate } \\
\text { of participation }\end{array}$ \\
\hline $\begin{array}{c}\text { Industrial } \\
\text { Radiography }\end{array}$ & $\begin{array}{c}\text { Radiographers / } \\
\text { Assistant radiographers }\end{array}$ & $\begin{array}{l}\text { Radiation Protection } \\
\text { in Industrial Radiography }\end{array}$ & 3 & $\begin{array}{c}\text { Certificate } \\
\text { of participation }\end{array}$ \\
\hline $\begin{array}{l}\text { Veterinary } \\
\text { Radiology }\end{array}$ & $\begin{array}{c}\text { Health } \\
\text { Professionals }\end{array}$ & $\begin{array}{l}\text { Radiation Protection } \\
\text { in Veterinary Radiology }\end{array}$ & 3 & $\begin{array}{c}\text { Certificate } \\
\text { of competence }\end{array}$ \\
\hline $\begin{array}{l}\text { Scrap Metal } \\
\text { Industries }\end{array}$ & $\begin{array}{c}\text { Portal } \\
\text { Operators }\end{array}$ & $\begin{array}{c}\text { Principles of Radiation } \\
\text { Detection (on-the-job-training) }\end{array}$ & 3 & $\begin{array}{c}\text { Certificate } \\
\text { of participation }\end{array}$ \\
\hline $\begin{array}{c}\text { Mineral extraction and } \\
\text { processing companies (NORM) }\end{array}$ & Operators & & 2 & $\begin{array}{c}\text { Certificate } \\
\text { of participation }\end{array}$ \\
\hline $\begin{array}{c}\text { Research activities: use } \\
\text { of sealed and unsealed sources }\end{array}$ & Operators & $\begin{array}{c}\text { Principles of } \\
\text { Radiation Protection }\end{array}$ & $<5$ & $\begin{array}{c}\text { Certificate } \\
\text { of participation }\end{array}$ \\
\hline $\begin{array}{c}\text { Security } \\
\text { Equipment }\end{array}$ & Operators & $\begin{array}{c}\text { Principles of Radiation } \\
\text { Detection (on-the-job-training) }\end{array}$ & $\begin{array}{l}\text { for all customs } \\
\text { in Greece }\end{array}$ & $\begin{array}{c}\text { Certificate } \\
\text { of participation }\end{array}$ \\
\hline
\end{tabular}

\section{Education and training at the International level}

Since 2003, the EEAE has acted as the IAEA's Regional Training Center (RTC) for "Radiation, Transport and Waste Safety" in Europe in the English language. Following the successful completion of the IAEA's Education and Training Appraisal Mission (EduTA) in 2008, a Long-Term Agreement (LTA) was signed in 2011 between the Hellenic Government and the IAEA to support the EEAE as an RTC in Europe. The LTA was ratified by Law (No. 4085, Official Gazette Folio No. 194, First issue) in October 2012. Moreover, since 2013 the EEAE has been recognized as the IAEA's Regional Training Center (RTC) in nuclear security in the English language.

The combination of being a regulatory authority and an IAEA RTC makes the EEAE the reference point in terms of education and training at the international level and national level.

The fulfillment of the EEAE's role as an RTC entails mainly:

(a) the organization and hosting of the IAEA's Postgraduate Educational Course on Radiation Protection and the Safety of Radiation Sources (PGEC). The course, lasting 18-22 weeks, follows the IAEA's Standard Syllabus (IAEA 2002);

(b) the organization and hosting of specialized training courses in various thematic areas, such as nuclear security, emergency response, radiation detection techniques, train-thetrainers, etc.;

(c) the provision of several months' internships and on-the-job training for scientists from various countries (IAEA fellowships) in the fields of radiation protection, regulatory control, dosimetry, calibration of ionizing radiation detectors and environmental radioactivity.

By the end of 2012, the EEAE had hosted 4 PGECs and 17 training courses/seminars. A total of 70 students have attended the PGECs, and a further 400 people have participated in seminars, workshops, scientific visits and internships.

The work of the EEAE in the field of education and training is recognized internationally. This is confirmed by the fact that its staff is invited to participate in international working groups and policy-makers' committees in this field. It is involved in the IAEA's steering committee on education and training, IAEA EduTA missions and IAEA workshops as invited experts and the Task Force on education and training of the HERCA (Heads of the European Radiological protection Competent Authorities). 


\section{Implementation of a quality management for the design, development and provision of non-formal education}

An effective national program for education and training in radiation protection assumes that the organization providing the education and training has a well-established quality management system.

The need for the implementation of a management system derives directly from the responsibilities of a regulatory body according to the IAEA (2011). Regulatory bodies have to establish, implement, assess and strive to continually improve a management system aligned with the goals of the regulatory body and contributing to the achievement of those goals. According to the IAEA (2011) the term "management system" reflects and includes the concept of 'quality control' (controlling the quality of products - learning services in our case) and its evolution through "quality assurance" (the system for ensuring the quality of products) and a "quality management" system (the system for managing quality).

The EEAE implements an integrated documented management system, as defined in (IAEA, 2006). Moreover, all of the EEAE's activities have been certified according to ISO 9001:2008 (ISO, 2008). In the framework of this system and complementary to it, the requirements for ISO/IEC 17025 (ISO, 2005) accreditation have been met in the EEAE for: (i) the measurements of personal dosimeters for external radiation to gamma fields, (ii) the calibration of equipment used in ionizing radiation fields, (iii) the gamma spectrometry and radon measurements and (iv) the non-ionizing measurements. Moreover, the inspection activities have been accredited according to the terms of ISO/IEC 17020:2012 (ISO, 2012), while the education and training activities were certified under the terms of ISO 29990:2010 (ISO, 2010) in 2013.

The ISO 29990:2010 standard specifies the basic requirements for learning services providers in non-formal education and training. This demands the involvement of scientific personnel, expert tutors and external experts in quality and auditing, under the supervision, guidance and financial support of the departments' administration. The management system mainly focuses on the design, provision and evaluation of the learning services which form a Plan-Do-Check-Act (PDCA) cycle (ISO, 2010):

(a) determining learning needs;

(b) design of the learning services;

(c) provision of the learning services;

(d) monitoring the delivery and evaluation of the learning services.

Compared with the methodology used for establishing a national program for education and training, as described in the previous paragraph, it can be concluded that the quality management system and the methodology have a similar structure. It can be considered that the quality management system is a miniature of the national program, as it corresponds to each learning service of the program. Well-organized, efficient and effective learning services lead to an efficient and effective educational national program, which in turn contributes to the building of a sustainable national radiation protection system.

\section{Methodology for assessment and evaluation of the training activities}

The existence of mechanisms for the assessment of individuals and the course evaluation are crucial parameters, according to both the national strategy and the quality management system developed. The term assessment is used in order to describe the measurement of the knowledge and/or skills and/or attitudes of an individual, while the term evaluation is related to the adequacy and effectiveness of a training activity or program.

Where the assessment of the knowledge of an individual is concerned, most of the training courses conducted include written examinations, specially designed for each particular group of participants. The assessment is based on multiplechoice or open-answer questions, reports on practical exercises and in some cases on the completion of a project.

The available evaluation mechanisms measure the effectiveness of the training activities at two levels: (a) in the evaluation of each individual course, and (b) in the evaluation of the whole strategy. Effectiveness in radiological protection and source safety can be difficult to assess in a short-term period and may rely on the monitoring of long-term trends (IAEA, 2012). To this end, each educational activity is evaluated independently through questionnaires addressed to both the participants and the lecturers concerning the quality and effectiveness of the training, while performance indicators such as the collective doses, the accident rate before and after training and the feedback from the employers are used for the evaluation of the whole program. At the national level, the feedback from EEAE inspectors on the level of adoption of a safety culture regime by the occupationally exposed personnel is considered to be important for the evaluation of the program, while at the international level, follow-up surveys monitoring the participants' professional development are conducted.

\section{Conclusions}

The EEAE, as reflected in this work, has a range of activities, in providing postgraduate and lifelong education and training on radiation protection and nuclear safety, at the national and international levels. The capacity of being simultaneously a regulatory authority and an IAEA RTC renders the EEAE a reference point in terms of education and training at both the national and international levels.

The EEAE has a strong commitment to building competence in radiation protection through education and training, which is acknowledged internationally. It makes a great effort in the provision of systematic education, training and retraining courses and dissemination of knowledge on new techniques and methodologies, addressed to the staff involved with ionizing radiation, since this is a key element in order to provide competence and ensure expertise in the field of radiation protection. The importance given to education and training by the EEAE is in accordance with the demands of the new European Basic Safety Standards.

The initiatives of the EEAE are further strengthened with the establishment of a national program for education and 
training. Moreover, a lot of effort has been and continues to be invested for the development and implementation of a fully customized management system ensuring the identification of learning needs, the design of learning content and processes, and the provision and evaluation of the learning services.

Acknowledgements. The authors would like to thank all EEAE staff for their crucial contribution to the educational activities described in this paper.

\section{References}

Council Directive 96/29/EURATOM (1996) Basic safety standards for the protection of the health of workers and the general public against the dangers arising from ionizing radiation Official Journal of the European Communities, ISSN 0378-6978, L 159, Vol. 39, 29.06.96.

Council Directive 97/43/EURATOM (1997) Health protection of individuals against the dangers of ionising radiation in relation to medical exposure. Official Journal of the European Communities, No. L 180/22-27, 9.07.97.

Council Directive 2013/59/EURATOM (2013) Basic safety standards for protection against the dangers arising from exposure to ionising radiation, and repealing Directives 89/618/EURATOM, 90/641/EURATOM, 96/29/EURATOM, 97/43/EURATOM and 2003/122/EURATOM 05.12.13.

Dimitriou P., Pafilis C., Karfopoulos K.L., Kamenopoulou V., Housiadas C.H. (2013) Establishing a national strategy for education and training in radiation protection. In: 5th International Conference on Education and Training in Radiological Protection, 12-15 March, Vienna, Austria.

EC (2010) Radiation Protection 116: Guidelines on education and training in radiation protection for medical exposures.

Economides S. (2013) Radiation Outside Workers; the current situation in Greece network, Economides, European ALARA Network Newsletter 33, 2.

Greek Radiation Protection Regulations (2001) Ministerial Order No1014, Official Gazette of the Greek Government No 216B.

IAEA (2001a) Building Competence in Radiation Protection and the Safe Use of Radiation Sources, Safety Guide No. RS-G-1.4, IAEA, Vienna.

IAEA (2001b) Safety Report Series No. 20, Training in Radiation Protection and the Safe Use of Radiation Sources, Vienna.
IAEA (2002) Training Course Series No. 18 (2002), Postgraduate Educational Course in Radiation Protection and the Safety of Radiation Sources, Standard Syllabus, IAEA, Vienna.

IAEA (2006) Safety Standards Series No. GS-R-3, The Management System for Facilities and Activities, IAEA, Vienna.

IAEA (2010a) Governmental, Legal and Regulatory Framework for Safety, General Safety Requirements Part1 No. GSR Part 1, IAEA, Vienna.

IAEA (2010b) Strategic Approach to Education and Training in Radiation, Transport and Waste Safety 2011-2020, Note 44.

IAEA (2011) Radiation Protection and Safety of Radiation Sources: International Basic Safety Standards, Safety Standards Series No. GSR Part 3 (Interim), Vienna.

IAEA (2012) Report No.12 - Steering Committee on Education and Training in Radiation Protection and Waste Safety, IAEA, Vienna.

ICRP Publication 113 (2009) Education and Training in Radiological Protection for Diagnostic and Interventional Procedures, Ann. ICRP 39 (5).

IRRS (2012) mission to Greece - Report, http://www.iaea. org/newscenter/pressreleases/2012/prn201212.html, http://www. eeae.gr/en/index.php?fvar=html/files/_irrs_mission_report.

ISO 9001:2008 (2008) Quality Management Systems Requirements.

ISO/IEC 17020:2012 (2012) Conformity assessment - Requirements for the operation of various types of bodies performing inspection.

ISO/IEC 17025:2005 (2005) General requirements for the competence of testing and calibration laboratories.

ISO 29990:2010 (2010) Learning services for non-formal education and training - Basic requirements for service providers.

Kamenopoulou V., Dimitriou P., Hourdakis C.J., Maltezos A., Matikas T., Potiriadis C., Camarinopoulos L. (2006) Nuclear security and radiological preparedness for the Olympic Games, Athens 2004: Lessons learned for organizing major public events, Health Phys. 91, 318-330.

Pafilis C., Kamenopoulou V., Maltezos A., Matikas T., Seferlis S., Dimitriou P. (2009) Education and training on nuclear security in Greece. In: 1st International Conference on Advancements in Nuclear Instrumentation, Measurement Methods and their Applications, Marseille, France, June 7-10, 2009 (IEEE), ISBN 978-1-4244-5208-8.

Cite this article as: K.L. Karfopoulos, E. Carinou, V. Kamenopoulou, P. Dimitriou, Ch. Housiadas. Building competence in radiation and nuclear safety through education and training - the approach of a national regulatory authority. Radioprotection 50(1), 59-64 (2015). 